\title{
Seasonal signatures in SFG vibrational spectra of the sea surface nanolayer at Boknis Eck Time Series Station (SW Baltic Sea)
}

\author{
K. Laß ${ }^{1}$, H. W. Bange ${ }^{2}$, and G. Friedrichs ${ }^{1,3}$ \\ ${ }^{1}$ Institute of Physical Chemistry, Kiel University, Max-Eyth-Str. 1, 24118 Kiel, Germany \\ ${ }^{2}$ GEOMAR Helmholtz Centre for Ocean Research Kiel, Düsternbrooker Weg 20, 24105 Kiel, Germany \\ ${ }^{3}$ KMS Kiel Marine Science - Centre for Interdisciplinary Marine Science Kiel University, Olshausenstr. 40, 24098 Kiel, \\ Germany
}

Correspondence to: K. Laß (lass@phc.uni-kiel.de)

Received: 25 December 2012 - Published in Biogeosciences Discuss.: 20 February 2013

Revised: 31 May 2013 - Accepted: 23 June 2013 - Published: 6 August 2013

\begin{abstract}
The very thin sea surface nanolayer on top of the sea surface microlayer, sometimes just one monomolecular layer thick, forms the interface between ocean and atmosphere. Due to the small dimension and tiny amount of substance, knowledge about the development of the layer in the course of the year is scarce. In this work, the sea surface nanolayer at Boknis Eck Time Series Station (BE), southwestern Baltic Sea, has been investigated over a period of three and a half years. Surface water samples were taken monthly by screen sampling and were analyzed in terms of organic content and composition by sum frequency generation spectroscopy, which is specifically sensitive to interfacial layers. A yearly periodicity has been observed with a pronounced abundance of sea surface nanolayer material (such as carbohydrate-rich material) during the summer months. On the basis of our results we conclude that the abundance of organic material in the nanolayer at Boknis Eck is not directly related to phytoplankton abundance alone. We speculate that indeed sloppy feeding of zooplankton together with photochemical and/or microbial processing of organic precursor compounds is responsible for the pronounced seasonality.
\end{abstract}

\section{Introduction}

The ocean surface is a very special part of the oceanic water column: forming the boundary between ocean and atmosphere, it is involved in all exchange processes between these phases. This includes exchange of energy (sunlight ir- radiation, heat exchange) and matter (gas transport, aerosol formation, precipitation). The upper millimeter of the water column, called the microlayer, exhibits special characteristics due to its interfacial character. Material scavenged from deeper layers by bubbles is enriched, and insoluble ("dry") surfactants as well as buoyant particles accumulate at the interface (Liss and Duce, 1997). The accumulation of organic material in connection with the pronounced exposure to the sunlight gives rise to enhanced photochemical processes (see e.g. Blough, 1997; Häder et al., 2011) and (micro)biological activity (see e.g. Cunliffe et al., 2011). The microlayer boundary to the atmosphere is formed by an even thinner layer $(1-10 \mathrm{~nm})$, the so-called nanolayer. It can be as thin as one molecular layer formed by surface-active substances. It is a place where certain surface-active substances as well as bouyant organics tend to accumulate. The properties of this layer may differ considerably from those of the underlying microlayer and determine the viscoelastic properties of the water-air interface (McKenna and Bock, 2006).

The nanolayer also has an effect on the air-sea gas exchange. It imposes (i) an additional diffusion barrier and (ii) influences the visco-elastic properties of the water surface. While the first effect is more important for aerosols, the latter impairs the gas exchange between ocean and atmosphere by wave damping and hence diminished turbulent gas transport (Liss and Duce, 1997). This has important implications for climate models relying on accurate estimates for the air-sea gas exchange of climate relevant atmospheric trace gases such as carbon dioxide, nitrous oxide, and others. 
Often it is assumed that high organic content in the upper water column goes along with the prevalence of a pronounced micro- and nanolayer (Frew, 1997). Surfactants found in the microlayer are mainly originating from phytoplankton exudates (see e.g. overviews in Wurl et al., 2011; Hunter, 1997). Hence, it is further hypothesized that a high concentration of chlorophyll in the water column can be taken as a direct indicator for pronounced, surfactantenriched microlayers (Asher, 1997) and nanolayers, leading to a decrease in gas exchange (see e.g. Duarte et al., 2009; Frew et al., 1990; Salter et al., 2011). A review of the current understanding of physicochemical aspects of the microlayer has been given recently by Cunliffe et al. (2013).

Despite this important implication, experimental data on the development of the nanolayer in the course of the year are very scarce. Partly this is due to difficulties in sampling and especially in chemical analysis of this very thin layer, which has been shown to be subject to high variability (Baier et al., 1974). To the best of our knowledge, a direct correlation between chlorophyll content and nanolayer abundance has not yet been proven explicitly. This study aims to show and interpret seasonal changes in amount and composition of the sea surface nanolayer at a coastal site in the southwestern Baltic Sea. Samples were analyzed with non-linear sum frequency generation spectroscopy, which has been quite recently established as a surface-specific tool for environmental ocean-air interfaces ( $\mathrm{La}$ et al., 2010; Laß and Friedrichs, 2011). Collected data serve as a step towards a more complete understanding of the state of the sea surface nanolayer in the course of the year, which is an important keystone for an improved parametrization of its role in the context of climate models.

\section{Basics}

\subsection{Surface-active substances in the sea surface microlayer: an overview}

Despite the difficulties in collecting and analyzing the sea surface microlayer substance pool, various approaches have been made to determine its composition. A brief summary of the present state of knowledge was given in our previous publication (Laß and Friedrichs, 2011). Briefly, the following substance classes have been identified as being abundant in the dissolved organic matter (DOM) fraction present in the microlayer (in descending order of fraction size):

- humic substances
- carbohydrate-rich material
- proteinaceous material
- lipids
- hydrocarbons (occasionally, from anthropogenic
sources)
In addition to the dissolved organic matter, fractions like gelatineous organic material (GOM) and other particulate organic material (POC) are present, often classified under various terms (such as transparent exopolymer particles (TEP), for example). An overview of the different classes of organic material involved in organic microlayer formation has been given by Wurl et al. (2011).

Non-linear optical methods provide a means of distinguishing nanolayer from microlayer substance. They are intrinsically surface specific (Lambert et al., 2005) and thus do not detect substance present in the bulk phase (which in this case translates to the microlayer). The method of vibrational sum frequency generation spectroscopy (VSFG) belongs to this group of analytical probes and yields structuredependent infrared (IR) spectra of molecules located directly at the interface.

\subsection{Sea surface nanolayer vibrational spectroscopy}

Recently, we demonstrated the feasibility of SFG spectroscopy for investigating the sea surface nanolayer $(\mathrm{Laß}$ et al., 2010) and published analyses of the resulting vibrational spectra (Laß and Friedrichs, 2011). Sampling sites were Boknis Eck Time Series Station, Tirpitz Harbour in Kiel and the pier of the GEOMAR institute located in the Kiel fjord. The main findings of this work can be summarised as follows:

1. An intensity reduction of the $\mathrm{OH}$ dangling bond signal at $3700 \mathrm{~cm}^{-1}$ indicates the presence of an organic monolayer on natural seawater samples.

2. Characteristic $\mathrm{CH}$ signals from alkyl-rich, probably lipid-like material have been detected.

3. The observed $\mathrm{CH}$ signal intensities suggest a fairly dense, lipid-rich monolayer with some degree of order.

4. More water soluble, so-called "wet" surfactants have been concluded to be dominant from a semiquantitative analysis of signal trends.

5. The order of the surface layer is retained even at very low surface coverages. This suggests a surface structure consisting of separate lipid-rich material containing surface areas (termed "islands" in surface science).

6. An unusual SFG signal enhancement at $3400-3500 \mathrm{~cm}^{-1}$ was discussed to originate either from $\mathrm{OH}$ rich compounds such as polysaccharides or to confined water molecules in a dense colloidal network. Its assignment to proteinaceous material is less likely.

7. The nanolayer composition showed low regional, but high temporal variability.

The present work extends this analysis to the use of SFG vibrational spectroscopy for recording and interpreting time 
series data on the base of the analysis of samples taken in the course of three and a half years. The study aims (i) to check if SFG spectroscopy in practice can serve as a tool to gain information on the seasonal development of the nanolayer, and (ii) to identify seasonal trends regarding spectral variations as well as total signal intensity.

\subsection{Sampling site}

Boknis Eck Time Series Station (BE) is located in the southwestern Baltic Sea near the entrance of Eckernförde Bay $\left(54^{\circ} 31^{\prime} \mathrm{N}, 10^{\circ} 02^{\prime} \mathrm{E}\right)$. The station site has a water depth of about $28 \mathrm{~m}$ and is located at a distance of roughly 1 nautical mile offshore. BE exhibits a pronounced stratification with a surface mixed layer restricted to upper $10-15 \mathrm{~m}$ during summer (Hansen et al., 1999). With negligible freshwater inflow this site is representative for the water conditions in the western Baltic Sea (Bange et al., 2011) which is characterised by regular water inflow from the North Sea.

Algal blooms are usually observed three times a year at $\mathrm{BE}$, in spring, summer and autumn. The spring bloom is usually the most pronounced one, whereas zooplankton activity and hence algal consumption is highest during summer (Smetacek, 1980; Smetacek et al., 1984).

Sampling and determination of various parameters (e.g. Secchi depth, CTD profiles, nutrient $/ \mathrm{O}_{2}$ measurements) takes place monthly since 1957 with only short interruptions (Bange et al., 2011). Surface monolayer sampling for vibrational spectroscopy has been performed since January 2009.

Sampling is done from R/V Littorina, a research vessel of $30 \mathrm{~m}$ length, while either anchored at BE or slowly moving around the sampling spot. Occasionally, research vessels Polarfuchs $(10 \mathrm{~m})$ and Alkor $(55 \mathrm{~m})$ were used for sampling as well. Screen sampling of the microlayer was accomplished from the side of the ship facing the surface water current induced by wind and waves.

\section{Experimental}

\subsection{Sampling method and procedure}

Sampling was performed on a monthly basis using the screen sampling method originally introduced by Garrett (1965) and standardized by the Intergovernmental Oceanographic Commission (IOC, 1985). Our sampling approach has been described and characterised previously (Laß et al., 2010). This method has been selected basically due to its simplicity of use and reliability with respect to deployment conditions and apparatus treatment. Briefly, a stainless-steel standard industrial analysis sieve mounted on a chain suspension of $30 \mathrm{~cm}$ diameter and ASTM MESH16 mesh width (Linker Industrietechnik, type 553055222056) was used for surface microlayer sampling. Sampling was performed by submersing the sieve in the water, moving it below the surface to a fresh spot of undisturbed surface and then pulling it through the water surface. In order to get rid of residual subsurface water adhering to the wire mesh frame, the sieve was at first tilted slightly to let it run off. The water held in the wire mesh by the surface tension was then recovered by strongly tilting the sieve. Typically, the sampled water from seven dips was pooled in one sample bottle and every sampling was repeated at least once.

The typical yield of one seven-dip sampling procedure was $150-250 \mathrm{~mL}$ of surface water, corresponding to an effective sampling depth of about $400 \mu \mathrm{m}$. The samples were transported to the laboratory and usually measured the same day, alternatively frozen to $-18^{\circ} \mathrm{C}$ and analyzed within two weeks. The data points acquired from samples subject to storage in frozen state did not exhibit any prominent behaviour and generally blended well within the other data points. For spectroscopy, the samples were poured into Teflon dishes measuring $14 \mathrm{~cm}$ in diameter and given a rest for at least 20 min prior to measurement to allow for equilibration between interface and aqueous phase. Details of the sampling procedure and consequences for the interpretation of the measured SFG signal intensity are outlined in our previous publications (Laß et al., 2010; Laß and Friedrichs, 2011). Briefly, taking into account the sampling efficiency as well as the ratio of the areas of the field sampler and the spectrometer dish, our specific procedure yielded samples with a theoretical surface concentration of dry surfactants 12.5 times as high as on the original sea surface. In contrast, as it can be concluded from stirring experiments outlined in the publication by ( $\mathrm{Laß}$ et al., 2010), the wet surfactant fraction of the surface-active matter is expected to re-establish surface - bulk adsorption equilibrium such that the measurements should largely reflect the concentration as present at sea. The wet-to-dry surfactant ratio can be estimated from SFG intensity ratios measured for samples pooled from a variable number of dips of the sieve. Following the data reduction procedure described by (Laß and Friedrichs, 2011), we deduced a natural wet-to-dry ratio of $12_{-5}^{+13}$ from 46 corresponding measurements performed throughout the sampling period. The stated uncertainty corresponds to error of the mean at $1 \sigma$ confidence level. Taking into account the 12.5 times enrichment of the dry fraction for the laboratory measurements, in average about half of the SFG signal intensity results from the dry surfactant fraction. Therefore, without independent measurements of the particular wet-to-dry surfactant ratio, the reported SFG intensities are a qualitative rather than absolute measure of nanolayer density. Note that a significant change of the wet-to-dry ratio during the course of the years could have biased the comparability of the SFG signal intensities. However, no obvious seasonal trend of the wetto-dry ratio were discernible from the variable dip experiments. Also note that the presented analysis of the seasonal nanolayer trends largely relies on the presence or absence of a nanolayer signal rather than on the absolute signal intensities. 


\subsection{SFG vibrational spectroscopy}

Analysis of the samples was performed with a commercial VSFG spectrometer (Ekspla). This device is based on a Nd:YAG laser producing pulses of about $30 \mathrm{ps}$ duration and finally delivering pulses of up to $325 \mu \mathrm{J}$ (VIS, $\lambda=532 \mathrm{~nm}$ ) and $200 \mu \mathrm{J}$ (tunable IR) at the sample. Both beams were focused onto the sample at incident angles of $53^{\circ}$ (IR) and $59^{\circ}$ (VIS) with respect to the surface normal, yielding a laser spot at the sample of less than $0.5 \mathrm{~mm}$. The generated sum frequency light was spatially and spectrally separated and detected by a photomultiplier. Typical SFG light intensities of the $\mathrm{C}-\mathrm{H}$ stretch modes for a dense wellordered lipid monolayer were on the order of 400 counts per laser pulse.

The absolute intensity of the generated SFG light is not only determined by the incoming light intensities and properties of the sample under examination, but also to fine details of the spectrometer adjustment, which is subject to slight variations. To account for these variations and drift on longer timescales, spectra of a $40 \AA^{2}$ molecule ${ }^{-1}$ dense Dipalmitoylphosphatidylcholine (DPPC) monolayer on water were recorded as an internal standard at the beginning and the end of each experimental day. VSFG spectra were normalized to the experimental VIS and IR intensities, and, finally, to the average of the $r^{+}$and $r_{\mathrm{FR}}^{+}$mode intensities taken from the DPPC standard spectrum. The reproducibility and stability of the SFG signal intensity can be stated as follows ( $\mathrm{Laß}$ et al., 2010):

- Direct repeatability is on the order of $8 \%$.

- Long-term stability derived from daily DPPC reference spectra measured over a period of six weeks is on the order of of $\pm 11 \%$ (including sample preparation repeatability).

The overall uncertainty of the measured signal intensity is estimated to be $\pm 15 \%$. Taking into account the non-linear relation between layer density and SFG signal intensity (i.e. a square dependence in the absence of structural changes at the interface; Lambert et al., 2005), this corresponds to an uncertainty in the concentration of surfactants on the order of $\pm 7 \%$. Actual signal variations measured for the time series samples were much higher and thus reflect significant changes in nanolayer abundance.

\section{Results}

\subsection{Spectra}

\subsubsection{CH bond signal}

Figure 1 shows mean spectra for March, August and October/November. All spectra exhibit the same characteristic

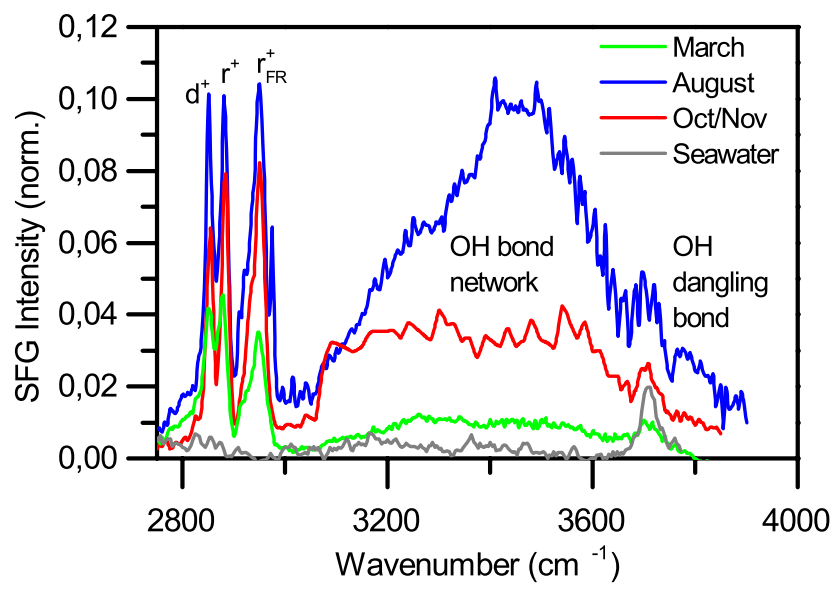

Fig. 1. Sea surface nanolayer spectra for March, August and October/November. These three spectra are averages representing 4-6 spectra each taken over three years in the respective months. For comparison, the (non-averaged) spectrum of a surfactant-free water sample from a depth of $25 \mathrm{~m}$ has been included as well. The labels indicate the different vibrational modes.

vibrational modes, although in different total and relative intensities. The spectral region below $3000 \mathrm{~cm}^{-1}$ exhibits three distinctive peaks, which are commonly attributed to symmetric stretch modes of methylene $\left(d^{+}\right)\left(2855 \mathrm{~cm}^{-1}\right)$ and methyl $\left(r^{+}\left(2880 \mathrm{~cm}^{-1}\right), r_{\mathrm{FR}}^{+}\left(2950 \mathrm{~cm}^{-1}\right)\right)$ groups as part of alkyl chains (Zhuang et al., 1999; Lu et al., 2004). The intensity relationship between these different modes is related to the conformation of the alkyl chains. For highly oriented, parallel chains, the $r^{+}$and $r_{\mathrm{FR}}^{+}$signal modes become dominant (Roke et al., 2003). In contrast, in the case of a totally disordered layer of alkyl chain carrying moieties, the overall signal is low and the $d^{+}$mode is dominating. The minor changes in the intensity pattern of these three signals even at reduced layer density indicate a nanolayer that is subject to little alterations regarding structure. In some cases an additional band has been observed at a wavenumber of $2920 \mathrm{~cm}^{-1}$; its origin will be addressed in more detail in Sect. 4.2.2.

\subsubsection{OH bond signal}

The frequency range from 3000 up to $3650 \mathrm{~cm}^{-1}$ is dominated by $\mathrm{OH}$ bond signal contributions. It usually appears as a very broad band with two intensity maxima. Despite extensive experimental and theoretical work, the origin of the band is still subject of ongoing research. Briefly, two alternative interpretations for the two-peak feature are discussed either assigning it to water molecules in "ice-like" (around $3200 \mathrm{~cm}^{-1}$ ) or "liquid-like" (around $3400 \mathrm{~cm}^{-1}$ ) hydrogen bonding molecular environments (Tian and Shen, 2009, and references therein) or a Fermi resonance between the symmetric stretch and the overtone of the $\mathrm{H}_{2} \mathrm{O}$ bending vibration (Nihonyanagi, 2011, and references therein). 
For clean seawater samples (i.e. in the absence of a pronounced organic nanolayer) we have found its intensity to be very low. In contrast, as depicted in the spectra shown in Fig. 1, the $\mathrm{OH}$ feature is quite intense when a well-formed organic layer is present. A noteworthy feature observed at certain times of the year is a high-intensity feature at 3400 $3500 \mathrm{~cm}^{-1}$ on top of the $\mathrm{OH}$ bond network band. Somewhat broadened in the averaged August spectra shown in Fig. 1, it appears as narrow pointed feature in single spectra. In our previous publication (Laß and Friedrichs, 2011), we have presented evidence for a connection of this feature with the presence of carbohydrate-rich material such as lipopolysaccharides.

The comparably narrow signal at $3700 \mathrm{~cm}^{-1}$ is attributed to free $\mathrm{OH}$ dangling bonds pointing out of the water surface. The pronounced presence of this feature indicates the absence of a nanolayer. It broadens and finally disappears when increasing amounts of organic material covers the waterair interface. This behaviour is also reflected in the spectra shown in Fig. 1.

\subsection{Seasonal variations}

\subsubsection{Overall signal trends}

Figure 2 illustrates the intensity trend of the VSFG spectra in the course of the sampling period. Figures $2 \mathrm{c}$ depicts the overall intensity of all $\mathrm{CH}$ modes below $3000 \mathrm{~cm}^{-1}$ and Fig. $2 \mathrm{~d}$ the intensities of the four most prominent $\mathrm{CH}$ stretch modes. Both plots reveal a pronounced increase of SFG intensity in the summer months, while the intensity in winter almost drops to zero. As the data did not reveal any obvious trend with respect to wind speed, wind direction, or wave height it is safe to assume that this overall annual trend is not biased by wind and wave induced short-term effects.

For comparison, both the oxygen concentration and saturation level at a water depth of $1 \mathrm{~m}$ are given in Fig.2a and the respective chlorophyll a concentration and the measured Secchi depth are displayed in Fig. 2b. At BE sampling site, the oxygen saturation typically exhibits well-pronounced maxima in spring. As it was shown in a previous publication (Smetacek et al., 1984), these maxima are related to the annual spring algal bloom and coincidentally coincide with the oxygen concentration maxima. This coincidence makes the much more pronounced $\mathrm{O}_{2}$ concentration maxima a more suitable spring algal bloom indicator than the oxygen saturation level itself. In contrast, these blooms are not reflected that well in the surface chlorophyll $a$ concentration, although occasionally a high chlorophyll $a$ concentration coincides with a high oxygen concentration. The partly mismatch between oxygen and chlorophyll $a$ concentrations results from the fact that chlorophyll $a$ concentrations only partly reflect the actual phytoplankton productivity. The Secchi depth, plotted in Fig. 2b, as a measure of turbidity (which at BE is mainly affected by the occurrence of algal populations), ex-

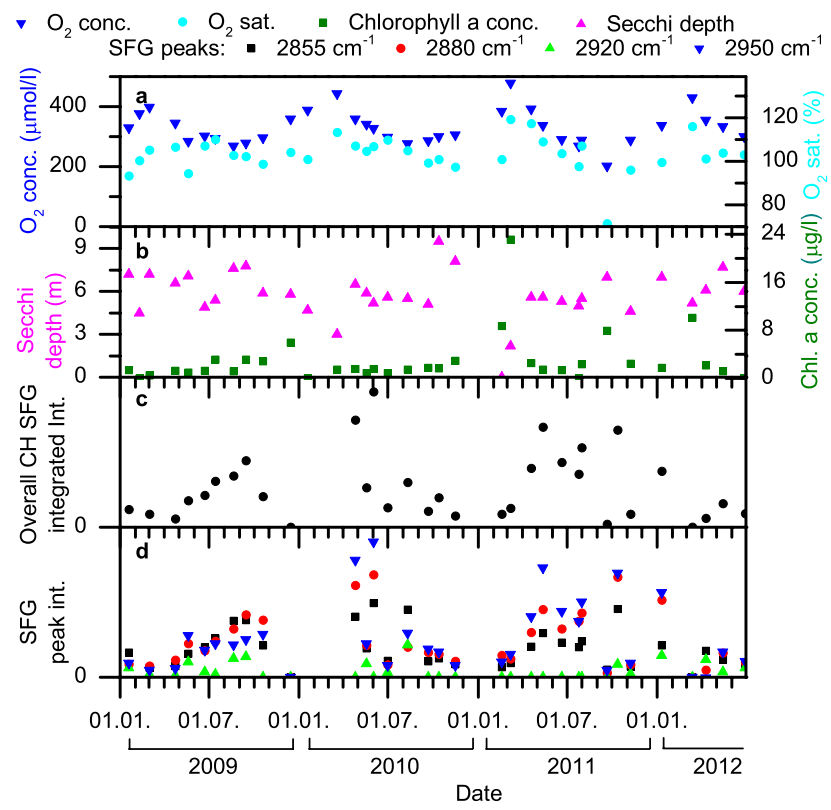

Fig. 2. Time series data of characteristic marine chemical parameters and SFG intensities. (a) Oxygen concentration and saturation at a water depth of $1 \mathrm{~m}$. (b) Secchi depth and chlorophyll $a$ concentration at a water depth of $1 \mathrm{~m}$. (c) Integrated SFG intensity over the $\mathrm{CH}$ stretch region. (d) SFG peak intensities for four different vibrational modes.

hibits minima in temporal coincidence with oxygen concentration maxima as well. Again, the natural scatter is substantial.

In line with our previous publication (Laß and Friedrichs, 2011), a comparison of surface water and subsurface water samples revealed a general tendency of much lower signal intensity and hence a depletion of surface active organic material with water depth.

\section{$4.2 .22920 \mathrm{~cm}^{-1}$ signal intensity and $\mathrm{OH}$ bond band}

In a number of spectra a peak appeared at $2920 \mathrm{~cm}^{-1}$. A conclusive assignment of this line is difficult. It may arise from the so-called $d^{-}$mode of methylene groups, carbohydraterich material (Laß and Friedrichs, 2011) or other $\mathrm{CH}$ containing substances. As already discussed above, the sharp intense feature of the $\mathrm{OH}$ bond band around $3450 \mathrm{~cm}^{-1}$, may arise from carbohydrate-rich material as well. Therefore, in order to challenge this carbohydrate hypothesis, we took a closer look to the corresponding peak intensity trends in Fig. 3. Figure $3 \mathrm{a}$ depicts the ratio of the signal intensities at $2920 \mathrm{~cm}^{-1}$ and $2880 \mathrm{~cm}^{-1}$ ( $r^{+}$mode), Fig. $3 \mathrm{~b}$ the intensity of the $\mathrm{OH}$ bond band at $3450 \mathrm{~cm}^{-1}$, and Fig. $3 \mathrm{c}$ the spectral position of the maximum of the $\mathrm{OH}$ bond band. Implications drawn from these plots are discussed in Sect. 5.2. 


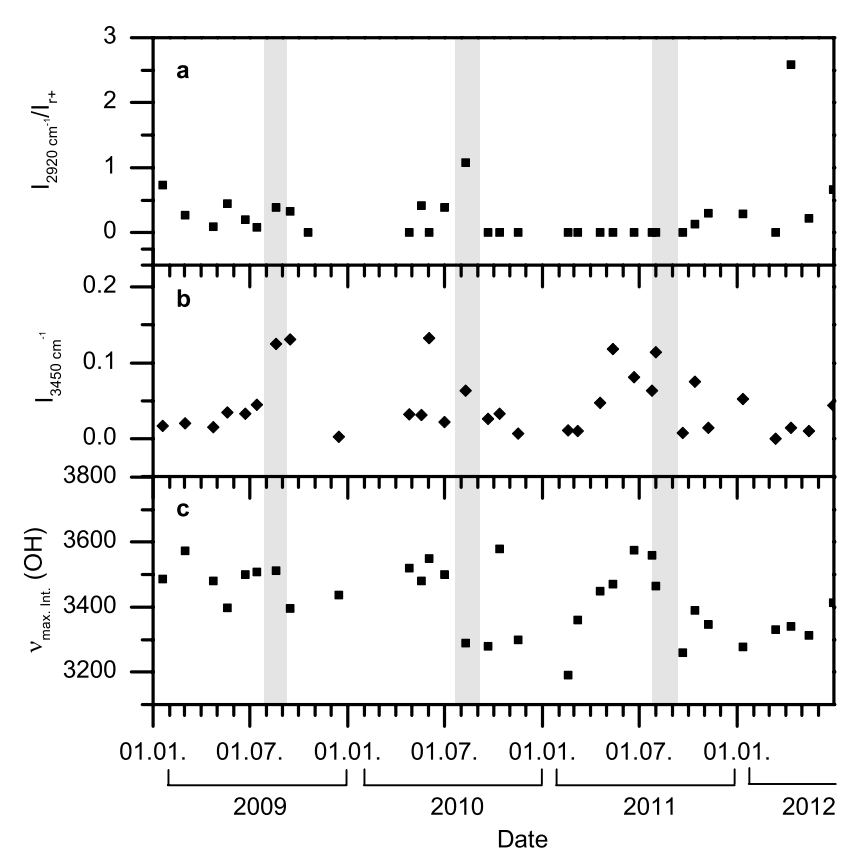

Fig. 3. Carbohydrate indications in spectral trends. (a) Relative intensity of the $\mathrm{CH}$ mode at $2920 \mathrm{~cm}^{-1}$, (b) intensity of the $\mathrm{OH}$ bond band at $3450 \mathrm{~cm}^{-1}$, and (c) wavenumber of maximum intensity of the $\mathrm{OH}$ bond band. The grey areas highlight the samples taken in August (see discussion in section 4.2.2).

\section{Discussion}

\subsection{Seasonality}

The time of the year with generally high layer intensity (see Fig. 2) appears to be early to midsummer (June and July), with higher intensities also occurring in the neighbouring months. This corresponds to a time lag of the order of two to three month with respect to the spring algal bloom. Efficient sedimentation of algal material after the spring bloom usually occurs at BE on the timescale of days to a week (Graf et al., 1983; Smetacek, 1980; Smetacek et al., 1984). Consequently, the high layer density cannot just be explained as an accumulation of algal decay residues from the spring bloom.

In order to better quantify this time lag, generic periodic model functions for the annual nanolayer intensity peak were constructed and checked for correlations with the experimental data. Either, a sinusoidal periodicity,

$I_{\text {sim }}(t, T)=\cos \left(\frac{2 \pi(t-T)}{365 \mathrm{~d}}\right)+1$,

or a repetitive Gaussian curve constructed by using the modulo operator,

$$
\begin{aligned}
& I_{\operatorname{sim}}(t, T, \sigma)=\frac{1}{\sigma \sqrt{2 \pi}} \\
& \cdot \exp \left(-\frac{1}{2} \frac{((t-T+182.5 \mathrm{~d}) \bmod 365 \mathrm{~d})-182.5 \mathrm{~d}}{\sigma}\right)^{2},
\end{aligned}
$$

has been assumed. $t$ corresponds to the respective day of the year, $T$ is the shift of the intensity maximum with respect to the turn of the year, $182.5 \mathrm{~d}$ is the duration of half a year, and $\sigma$ depicts the width of the Gaussian curves. $\sigma$ is related to the full width at half maximum by FWHM $=2 \sqrt{2 \ln 2} \sigma \approx 2.35 \sigma$. Note that the shift of the Gaussian function by half a year (and reverse) was necessary in order to set the point of discontinuity in-between the maxima.

The cross-correlation function of the simulated intensity values with the measured $\mathrm{CH}$ intensity values, generally reflecting similarity of these functions, was calculated according to

$\rho(T)=\sum_{i=0}^{n} I_{\mathrm{Sim}}\left(t_{i}, T, \sigma\right) \times I_{\mathrm{SFG}}\left(t_{i}\right) \times \Delta t_{i}$.

Here, $t_{i}$ is the $i$ th value of the measurement date, $I_{\mathrm{SFG}}\left(t_{i}\right)$ the corresponding SFG intensity, and $\Delta t_{i}$ the timespan the data point is representing, $\Delta t_{i}=\left(t_{i+1}-t_{i-1}\right) / 2$. The maximum of the corresponding function yields the mean day of the year where a maximum of the SFG intensity is to be expected. In order to compare the quality of the different model functions, the correlation coefficient has been normalized according to

$R=\rho(t) / \sqrt{\frac{1}{4} \sum_{i=0}^{n} I_{\text {sim }}^{2}\left(t_{i}, T, \sigma\right) \Delta t_{i} \sum_{i=0}^{n} I_{\mathrm{SFG}}^{2}\left(t_{i}\right) \Delta t_{i}}$.

Figure 4 compares these model functions with the experimental data. Setting $\sigma=25 \mathrm{~d}$, the maximum of the cross-correlation function is found at day 126 of the year (i.e. 6 May, short-dashed curve in Fig. 4a) with a low value of $R=0.729$. Obviously, this narrow model function has its maximum earlier than the SFG intensity, overestimates the significance of single high data points, and therefore it is not a good representation of the measured time series. The best correlation with the Gaussian model function is found with a broader distribution of $\sigma=50 \mathrm{~d}$ and yields $R=0.762$ and a maximum at day 141 of the year (i.e. 21 May, dashed curve). An even better correlation with $R=0.794$ was obtained by the simple sinusoidal function (Eq. 4) with a maximum at day 155 (i.e. 4 June, solid curve).

The oxygen concentration data were fitted to a sine function by a non-linear Levenberg-Marquardt least square fit as shown in Fig. 4b of Fig. 4. The mean value of the day of the maximum oxygen concentration determined using this procedure is day 79 of the year (i.e. mid-March) and indicates the climax of the spring algal bloom (see Sect. 2.3). So the average time lag between the spring algal bloom and the SFG spectral intensity is about two and a half months $(T=76 \mathrm{~d}$, assuming the best fitting sinusoidal model). Although this time lag should be considered a rough estimate with considerable uncertainty, the separation is so large such that algal exudates or decomposition products from the spring bloom cannot serve as an explanation for the intense nanolayer formation at this time. 


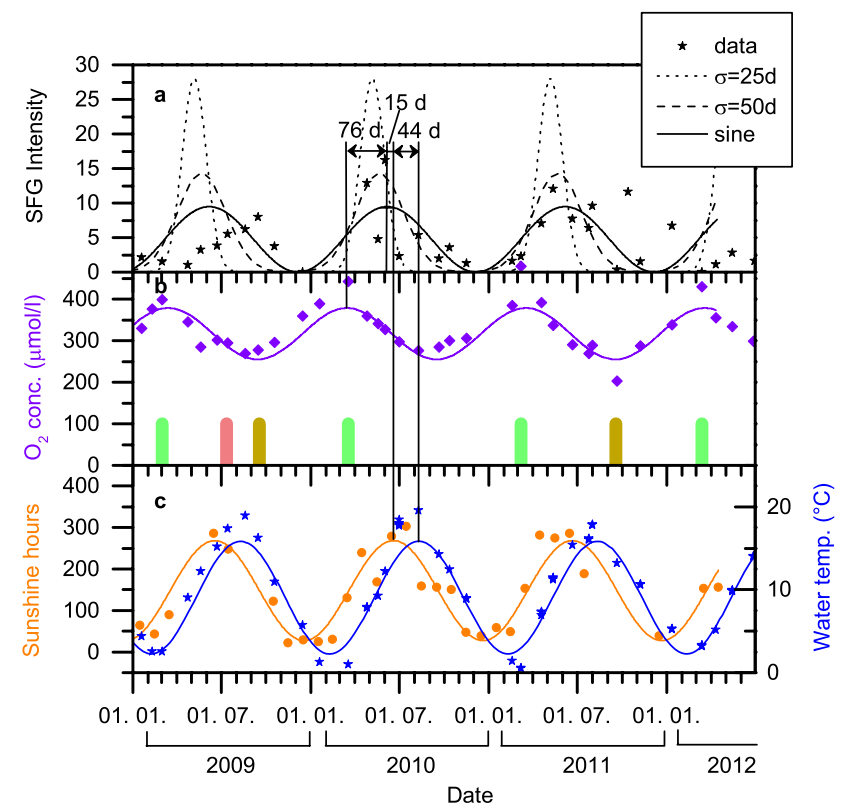

Fig. 4. Analysis of seasonal trends. (a) Overall SFG intensity in comparison with periodic model functions. (b) Oxygen concentration. The bars indicate spring (green), summer (red) and autumn (brown) algal blooms, as far as the data were available. (c) Sunshine duration of the respective months and surface water temperature together with sinusoidal fits.

In order to evaluate a possible role of solar irradiation within the process of nanolayer formation, the duration of sunshine for each month was taken from the online weather/climate data archives of the "Deutscher Wetterdienst" (DWD) (DWD, 2012) for the offshore station "Leuchtturm Kiel" " $\left(54^{\circ} 31^{\prime} 12^{\prime \prime} \mathrm{N}, 10^{\circ} 24^{\prime} 24^{\prime \prime} \mathrm{E}\right.$, about $16 \mathrm{~km}$ away from $\mathrm{BE}$ ). A fit of a sine function to the number of sunshine hours yields a maximum at day 167 of the year (i.e. mid of June; see Fig. 4c). Within uncertainty limits, this is identical to the time of the SFG intensity maximum in the year. This may well indicate that the accumulation of organic matter on the sea surface is related to the photochemical degradation of material already present within the microlayer, however, such a straightforward interpretation is far from being conclusive.

In this regard, it should also be mentioned that the maximum of the SFG signal intensity and the maximum of the surface water temperature are separated by ca. 2 months (Fig. 4a and c), with the SFG intensity maximum ahead of the water temperature maximum. Although the order of the maxima suggests otherwise, the possibility should be taken into account that the increased appearance of organic surfactant material is related to generally increasing microbial productivity as result of the warmer surface water: bacterial abundance at BE is closely related to water temperatures (Hoppe et al., 2013) implying that during summer the bacterial abundance is enhanced. Thus, we speculate that bacteria blooms and the associated grazing by protozoans (see e.g. Kuosa and Kivi, 1989; Kuuppo-Leinikki, 1990) may affect the appearance of organic surfactants in summer. Unfortunately, neither measurements of bacterial abundance nor experiments about protozoan grazing are available for BE during the sampling period discussed here.

In fact, during the summer months phytoplankton production at BE is closely associated with high zooplankton stocks (Smetacek et al., 1984; Smetacek, 1980). This is in contrast to the spring bloom when the organic material is very effectively sedimented and zooplankton stocks are low. Thus we suggest that the SFG intensity maximum in the summer may result from zooplankton grazing on phytoplankton during which organic compounds are not assimilated or respired but released from broken cells to the water column (so-called sloppy feeding) and/or excretion and fecal pellet leaching (see e.g. Møller, 2005; Strom et al., 1997). Organic compounds which are released during zooplankton grazing on phytoplankton can, therefore, accumulate in the micro/nanolayer where it, in turn, may be photochemically and/or microbiologically degraded.

\subsection{Role of carbohydrates}

As it is visible in Fig. 1 and further analyzed in Fig. 3, beside the signal intensity pattern, notable changes in the appearance of the spectrum in the course of the year are also present. The question arises if these spectral changes can be related to an increased abundance of carbohydrate-rich polymeric material in summer. As already discussed, both bands at $2920 \mathrm{~cm}^{-1}$ and $3450 \mathrm{~cm}^{-1}$ may be attributable to carbohydrate material.

A direct comparison of the relative $\mathrm{CH}$ signal strengths of the $2920 \mathrm{~cm}^{-1}$ band and the intensity of the $3450 \mathrm{~cm}^{-1}$ band is presented in Fig. 3a and b. No regular pattern is observed for the $2920 \mathrm{~cm}^{-1}$ band, whereas high-intensity $\mathrm{OH}$ bond bands consistently show up in the summer months. Moreover, the spectral position of the $\mathrm{OH}$ bond maximum preferentially is found at higher wavenumbers during summer. The latter can be associated with the presence of the pointed $\mathrm{OH}$ bond band feature around $3450 \mathrm{~cm}^{-1}$, which was particularly visible around August over the three years of the study.

In our recent publication (Laß and Friedrichs, 2011), we have shown evidence from lab proxy experiments using Xanthan gum that the $3450 \mathrm{~cm}^{-1}$ spectral feature might be related to the increased presence of carbohydrate containing compounds, especially (lipo-)polysaccharides and/or TEPlike material. It may arise directly from the $\mathrm{OH}$ bonds of carbohydrates or from confined water molecules embedded in colloidal hydrogen-bonded carbohydrate networks. Combined with the regular observation of this feature in $\mathrm{Au}-$ gust, the conclusion seems straightforward that high concentrations of carbohydrates are present in the nanolayer during this time of the year. As opposed to this, relying upon this carbohydrate hypothesis, the irregular appearance of the 
$2920 \mathrm{~cm}^{-1}$ feature would disqualify the $\mathrm{CH}$ signal to be carbohydrate specific. Clearly, future studies are needed with simultaneous analysis of carbohydrate content in order to narrow down the room for interpretation.

Whatever the case may be, as carbohydrate-rich wet surfactants should be (more or less) in equilibrium with the corresponding carbohydrate concentration in solution, elevated levels of carbohydrates in the nanolayer should correspond to increased levels of carbohydrates in the microlayer as well. To the best of our knowledge, such a seasonal trend has not been reported in the literature so far. In contrast, a recent detailed chemical characterization of carbohydrates and other dissolved organic compounds in the microlayer and the underlying bulk water of the Baltic Sea by van Pinxteren et al. (2012) came to the conclusion that carbohydrate levels are neither enriched in the microlayer nor increased during summer. Unfortunately, in that paper all conclusions had to be based on only three sampling dates (one set of samples each for summer 2006, winter 2008 and spring 2008) and the single compound analysis was restricted to monosaccharides, monosaccharide anhydrates and sugar alcohols. Therefore, it might well be questioned whether the analyzed carbohydrates are representative for the total carbohydrate pool, which is dominated by marine polymer gels. Most importantly, their analytical procedures were not designed to distinguish between substances emanating from the micro- or the nanolayer. Therefore, it remains unclear whether their microlayer-specific results can directly be related to our nanolayer-specific measurements.

\subsection{Possible anthropogenic bias}

It might be questioned whether structure and intensity of the presented nanolayer measurements may be influenced by anthropogenic factors. For Eckernförde Bay, the potential main anthropogenic contributions stems from naval traffic and from recreational beach tourism activities. However, samples taken from a visible oil spill in Kiel naval harbour showed that the influence on the SFG layer spectra is comparably small ( $\mathrm{Laß}$ and Friedrichs, 2011). To the best of our knowledge no major oil spill happened in the open waters of Eckernförde Bay during our study and we did not observe any oil spill in the sampling area. Bathing tourism deserves a closer look, as Baier et al. (1974) have observed an increase in layer intensity on smaller lakes after weekends with a lot of recreational activity. As bathing tourism might be suspected to introduce a lot of suncream residues into the seawater, we have recorded spectra of suncream spread on water in the laboratory. They showed no indication for the unusual spectral feature around $3450 \mathrm{~cm}^{-1}$. Furthermore, we looked for a relation of the SFG signal intensity to the total number of touristic overnight stays at the nearby city of Eckernförde (taken from Elmenhorst, 2012, Table 1). In order to identify whether high layer intensities coincide with high bathing touristic activity, we weighted the number of touristic stays with the monthly average of the maximum air temperature as a proxy for bathing activity. Generally peaking in July and August (and therefore much later than the SFG intensity), no significant correlation could be found with the seasonal trend nor single data points. We therefore conclude that an anthropogenic bias in our data is unlikely.

\section{Conclusions}

From our analysis and discussion of VSFG spectra and accompanying marine chemical parameters of water samples taken at Boknis Eck Time Series Station, we draw the following conclusions:

- Non-linear vibrational SFG spectroscopy is well suited to collect time series data of surface IR spectra. Reproducibility of SFG signal intensity is more than sufficient to monitor the high natural variability of SFG nanolayer response.

- Sea surface nanolayer material is most abundant in the summer months and appears with a time lag of about 2.5 months with respect to the spring algal bloom. VSFG spectra intensity declines in autumn and decays to almost zero during winter.

- High phytoplankton abundance alone cannot serve as an explanation for pronounced surfactant layers.

- We suggest that sloppy feeding of zooplankton and/or microbial processes may result in a pronounced accumulation of organic material in the nanolayer during the summer months.

- As periods of high sunlight abundance coincide with periods of high layer intensity, the role of photochemical processing of organic precursor compounds remains to be investigated.

- Changes in the appearance of the spectra indicate changes in the chemical composition and structure of the nanolayer in the course of the year. Accumulation of carbohydrate-rich material in the late summer may serve as an explanation.

The results demonstrate that nanolayer abundance is not directly related to the phytoplankton abundance. Most probably, biochemical and/or photochemical transformation of organic substances is an important factor in layer formation. To gain further insight into nanolayer formation and to advance the interpretation of vibrational SFG spectra of natural nanolayers, simultaneous SFG measurements and chemical analysis of microlayer substances (such as carbohydrates, amino acids, etc.) are needed. Corresponding measurements are underway. Moreover, in order to draw more general conclusions, extension of SFG analysis to surface water samples 
collected at remote locations and different marine provinces is desirable.

Acknowledgements. We thank captains and crews of the research vessels Littorina, Alkor and Polarfuchs for their support during the sampling cruises. Thanks also to Meike Becker for help with the processing of the oxygen data and Arne Körtzinger and Cathleen Zindler for valuable discussions. We thank Frank Malien and the $\mathrm{BE}$ team for providing the $\mathrm{CTD}, \mathrm{O}_{2}$, and Secchi depth measurements as well as Ulf Riebesell who supported the chlorophyll $a$ measurements. We acknowledge the Deutscher Wetterdienst (DWD) for making archival weather/climate data available online. We also thank the German Science Foundation for financial support in the framework of the cluster of excellence "The Future Ocean" (DFG-EC80), and the referees for valuable comments. The Boknis Eck Time Series Station is run by the Marine Biogeochemistry Research Division at GEOMAR.

Edited by: S. W. A. Naqvi

\section{References}

Asher, W.: Chemistry of the sea-surface microlayer, in: The Sea Surface and Global Change, edited by: Liss, P. S. and Duce, R. A., chap. 5, Cambridge University Press, Cambridge, 251-286, 1997.

Baier, R. E., Goupil, D. W., Perlmutter, S., and King, R.: Dominant chemical composition of sea-surface films, natural slicks, and foams, J. Rech. Atmos., 8, 571-600, 1974.

Bange, H. W., Dale, A., Hansen, H. P., Karstensen, J., Malien, F., Petereit, C., Laß, K., and Friedrichs, G.: Boknis Eck Time Series Station (SW Baltic Sea): Measurements from 1957 to 2010, LOICZ Inprint, 16-22, 2011.

Blough, N. V.: Photochemistry in the sea-surface microlayer, in: The Sea Surface and Global Change, edited by: Liss, P. S. and Duce, R. A., chap. 5, Cambridge University Press, Cambridge, 383-242, 1997.

Cunliffe, M., Upstill-Goddard, R. C., and Murrell, J. C.: Microbiology of aquatic surface microlayers, FEMS Microbiol. Rev., 35, 233-246, doi:10.1111/j.1574-6976.2010.00246.x, 2011.

Cunliffe, M., Engel, A., Frka, Sanja, Gašparović, Blaženka, Guitart, C., Murrell, J. C., Salter, M., Stolle, Ch., UpstillGoddard, R. C., and Wurl, O.: Sea surface microlayers: A unified physicochemical and biological perspective of the air-ocean interface, Prog. Oceanogr., 109, 104-116, doi:10.1016/j.pocean.2012.08.004, 2013.

Duarte, C. M., Praerie, Y. T., Agustí, S., and Herndl, G. J.: Evidence for surface organic matter modulation of air-sea $\mathrm{CO}_{2}$ gas exchange, Biogeoscience, 6, 1105-1114, doi:10.5194/bg-6-11052009, 2009.

DWD: http://www.dwd.de/klimadaten, last access: 22 December 2012, 2012.

Elmenhorst, R.: Gutachten zur Neugestaltung der Fremdenverkehrsabgabesatzung der Stadt Eckernförde, Report, Bochum, available at: http://ris.eckernfoerde.de/sdoffice/ pdfdocs/T10777B.pdf, and ris.eckernfoerde.de/sdoffice/pdfdocs/ T10777C.pdf, last access: 22 December 2012.
Frew, N. M.: The role of organic films in air-sea gas exchange, in: The Sea Surface and Global Change, edited by: Liss, P. S. and Duce, R. A., chap. 5, Cambridge University Press, Cambridge, 121-172, 1997.

Frew, N. M., Goldman, J. C., Dennett, M. R., and Johnson, A. S.: Impact of phytoplankton-generated surfactants on air-sea gas exchange, J. Geophys. Res., 95, 3337-3353, doi:10.1029/JC095iC03p03337, 1990.

Garrett, W. D.: Collection of slick-forming materials from the sea surface, Limnol. Oceanogr., 10, 602-605, doi:10.4319/lo.1965.10.4.0602, 1965.

Graf, G., Schulz, R., Peinert, R., and Meyer-Reil, L. A.: Benthic response to sedimentation events during autumn to spring at a shallow-water station in the western Kiel Bight, I. Analysis of processes on a community level, Mar. Biol., 77, 235-246, doi:10.1007/BF00395813, 1983.

Hansen, H. P., Giesenhagen, H. C., and Behrends, G.: Seasonal and long-term control of bottom water oxygen deficiency in a stratified shallow coastal system, ICES J. Mar. Sci. Suppl., 56, 65-71, 1999.

Häder, D.-P., Helbling, E. W., Williamson, C. E., and Worrest, R. C.: Effects of UV radiation on aquatic ecosystems and interactions with climate change, Photochem. Photobiol. Sci., 10, 242-260, doi:10.1039/C0PP90036B, 2011.

Hoppe, H.-G., Giesenhagen, H. C., Koppe, R., Hansen, H.-P., and Gocke, K.: Impact of change in climate and policy from 1988 to 2007 on environmental and microbial variables at the time series station Boknis Eck, Baltic Sea, Biogeosciences, 10, 4529-4546, doi:10.5194/bg-10-4529-2013, 2013.

Hunter, K. A.: Chemistry of the sea-surface microlayer, in: The Sea Surface and Global Change, edited by: Liss, P. S. and Duce, R. A., chap. 5, Cambridge University Press, Cambridge, 287-320, 1997.

Intergovernmental Oceanographic Commission: Procedure for sampling the sea-surface microlayer, New York, http://unesdoc.unesco.org/ulis/cgi-bin/ulis.pl?catno= 65956\&set=48B80F97_2_114\&gp=1\&mode=e\&lin=1, last access: 22 December 2012, 1985.

Kuosa, H., and Kivi, K.: Bacteria and heterotrophic flagellates in the pelagic carbon cycle in the northern Baltic Sea, Mar. Ecol.-Prog. Ser., 53, 93-100, 1989.

Kuuppo-Leinikki, P.: Protozoan grazing on planktonic bacteria and its impact on bacterial population, Mar. Ecol.-Prog. Ser., 63, 227-238, 1990.

Lambert, A. G., Davies, P. B., and Neivandt, D. J.: Implementing the theory of sum frequency generation vibrational spectroscopy: a tutorial review, Appl. Spec. Rev., 40, 103-145, doi:10.1081/ASR-200038326, 2005.

Laß, K. and Friedrichs, G.: Revealing structural properties of the marine nanolayer from vibrational sum frequency generation spectra, J. Geophys. Res., 116, C08042, doi:10.1029/2010JC006609, 2011.

Laß, K., Kleber, J., and Friedrichs, G.: Vibrational sum frequency generation as a probe for composition, chemical reactivity, and film formation dynamics of the sea surface nanolayer, Limnol. Oceanogr.-Meth., 8, 216-228, doi:10.4319/lom.2010.8.216, 2010.

Liss, P. S. and Duce, R. A. (Eds.): The Sea Surface and Global Change, Cambridge University Press, Cambridge, 1997. 
Lu, R., Gan, W., Wu, B. H., Chen, H., and Wang, H. F.: Vibrational polarization spectroscopy of $\mathrm{CH}$ stretching modes of the methylene group at the vapor/liquid interfaces with sum frequency generation, J. Phys. Chem. B, 108, 7297-7306, doi:10.1021/jp036674o, 2004.

McKenna, S. P. and Bock, E. J.: Physicochemical effects of the marine microlayer on air-sea gas transport, in: Marine Surface Films: Chemical Characteristics, Influence on Air-Sea Interactions and Remote Sensing, edited by: Gade, M., Hühnerfuss, H., and Korenowski, G., Springer, Berlin, Heidelberg, 77-91, 2006.

Møller, E. F.: Sloppy feeding in marine copepods: prey-sizedependent production of dissolved organic carbon, J. Plankton Res., 27, 27-35, doi:10.1093/plankt/fbh147, 2005.

Nihonyanagi, S., Ishiyama, T., Lee, T.-K., Yamaguchi, S., Bonn, M., Morita, A., and Tahara, T.: Unified Molecular View of the Air/Water Interface Based on Experimental and Theoretical $\chi^{(2)}$ Spectra of an Isotopically Diluted Water Surface, J. Am. Chem. Soc., 133, 16875-16880, doi:10.1021/ja2053754, 2011.

Roke, S., Schins, J., Müller, M., and Bonn, M.: Vibrational spectroscopic investigation of the phase diagram of a biomimetic lipid monolayer, Phys. Rev. Lett., 90, 128101, doi:10.1103/PhysRevLett.90.128101, 2003.

Salter, M. E., Upstill-Goddard, R. C., Nightingale, P. D., Archer, D. S., Blomquist, B., Ho, T. D., Huebert, B., Schlosser, P., and Yang, M.: Impact of an artificial surfactant release on air-sea gas fluxes during Deep Ocean Gas Exchange Experiment II, J. Geophys. Res., 116, C11016, doi:10.1029/2011JC007023, 2011.
Smetacek, V.: Annual cycle of sedimentation in relation to plankton ecology in western Kiel Bight, Ophelia, Suppl. 1, 65-76, 1980.

Smetacek, V., von Bodungen, B., Knopper, B., Peinert, R., Pollehne, F., Stegmann, P., and Zeitzschel, B.: Seasonal stages characterizing the annual cycle of an inshore pelagic system, Rapp. P.-V. Reun. Cons. Int. Explor. Mer, 183, 126-135, 1984.

Strom, S. L., Benner, R., Ziegler, S., and Dagg, M. J.: Planktonic grazers are a potentially important source of marine dissolved organic carbon, Limnol. Oceanogr., 42, 1364-1374, doi:10.4319/lo.1997.42.6.1364, 1997.

Tian, C. S., and Shen, Y. R.: Sum-frequency vibrational spectroscopic studies of water/vapor interfaces, Chem. Phys. Lett., 470, 1-6, doi:10.1016/j.cplett.2009.01.016, 2009.

van Pinxteren, M., Müller, C., Iinuma, Y., Stolle, C., and Herrmann, H.: Chemical characterization of dissolved organic compounds from coastal sea surface microlayers (Baltic Sea, Germany), Environ. Sci. Technol., 46, 10455-10462, doi:10.1021/es204492b, 2012.

Wurl, O., Wurl, E., Miller, L. Johnson, K., and Vagle, S.: Formation and global distribution of sea-surface microlayers, Biogeosciences, 8, 121-135, doi:10.5194/bg-8-121-2011, 2011.

Zhuang, X., Miranda, P. B., Kim, D., and Shen, Y. R.: Mapping molecular orientation and conformation at interfaces by surface nonlinear optics, Phys. Rev. B, 59, 12632-12640, doi:10.1103/PhysRevB.59.12632, 1999. 